\title{
Administration of Vasoconstrictor, But Not Volume Expander Prevents Maternal Hypotension During Spinal-Epidural Anesthesia For Elective Cesarean Section
}

\author{
Chen $\mathrm{J}^{1}$, Lan $\mathrm{Q}^{1}$, Jin $\mathrm{S}^{2}$, Zeng $\mathrm{X}^{3^{*}}$ and Zhan $\mathrm{H}^{1}$ \\ ${ }^{1}$ Department of Anesthesia, The Third affiliated hospital of Guangzhou Medical University, Guangzhou, China \\ ${ }^{2}$ Department of Anesthesia, The Sixth affiliated hospital of Sun Yat-Sen University, Guangzhou, China \\ ${ }^{3}$ Department of Pathology and Laboratory Medicine, Temple University, Philadelphia, USA
}

*Corresponding author: Zeng X, MD, PhD, Temple University Hospital, Department of Pathology and Laboratory Medicine, 3401 North Broad Street - Room A2-F326, 2PAP, Philadelphia, Pennsylvania 19140, USA,E-mail: xu.zeng@tuhs.temple.edu

Citation: Chen J, Lan Q, Jin S, Zeng X, Zhan H (2016) Administration of Vasoconstrictor, but not Volume Expander Prevents Maternal Hypotension during Spinal-Epidural Anesthesia for Elective Cesarean Section. SAJ Cas Rep 3: 102

Article history: Received: 15 January 2016, Accepted: 14 February 2016, Published: 16 February 2016

\section{Abstract}

Objective: To determine the best management option for preventing maternal hypotension after combined spinal-epidural anesthesia (CSEA) in elective cesarean section patients.

\begin{abstract}
Methods: A total of 240 full-term, single pregnancy women, undergoing elective cesarean section in CSEA were included. Multiple linear regression analysis was used to identify major contributing factors for maternal hypotension from 18 independent variables. The model was set as $\alpha_{\text {entry }}=0.05, \alpha_{\text {remove }}=0.15$, and condition index $<15$. The incidence of hypotension from different combinations of vasoconstrictors for hypotension prevention were calculated and compared, then correlated with $\mathrm{pH}$ and base excess in neonatal umbilical venous blood, as well as 1 and 5 min Apgar score, using one-way ANOVA. $p<0.05$ was considered to be significant difference.

Results: From the Multiple linear regression equation generated by Model 3 (Incidence of hypotension $=1.033-29.984 \times$ continuous dose of phenylephrine $+1.095 \times$ phenylephrine total $-0.779 \times$ management of vasoconstrictor, adjusted $\mathrm{R}^{2}=0.911$ ), the continuous dosage of phenylephrine was identified as the main factor for the incidence of maternal hypotension after CSEA for elective cesarean section. The incidence of hypotension was significantly lower $(\mathrm{p}<0.05)$ in the group of patients treated with continue maintenance dose of phenylephrine $(0.88 \pm 1.17)$ than patients with single bolus of phenylephrine $(2.67 \pm 1.81)$ or with preventive single bolus of phenylephrine (3.53 \pm 2.02$)$. The $\mathrm{pH}$ of neonatal umbilical venous blood in patients using phenylephrine continuously was significant higher than patients without phenylephrine continuously $(P<0.05)$. There were no significant difference $(P>0.05)$ in base excess of umbilical venous blood, Apgar1 and Apgar5 of the newborn between groups.
\end{abstract}

Conclusions: Continuous dosage of phenylephrine decrease incidence of maternal hypotension after CSEA for elected cesarean section.

Keywords: Hypothyroidism; Myxedema Madness; Psychosis

\section{Introduction}

Hypotension is a common side effect induced by combined spinal and epidural anesthesia (CSEA) during cesarean section [1,2]. As elective cesarean section becomes a popular procedure in obstetric delivery worldwide, higher incidence of CSEA-induced hypotension has been reported in recent years [1,3]. Prolonged hypotension during cesarean section can cause harm to mother and fetus [2]. Hence, maintaining blood pressure in normal range during cesarean section after CSEA is important and becomes a hot topic in current clinical research. A lot of factors have been shown to involve in the CSEA-induced hypotension during cesarean section [3]. Up to date, most studies focus only on a single or a few aspects of CSEA-induced hypotension during cesarean section [2-12], so the findings from these studies are less clinical value. In present study, using multiple linear regression analysis, many important factors which might potentially affect CSEA-induced hypotension during cesarean section were analyzed. Among these, we found that the continuous administration of phenylephrine is the most effective treatment for prevention of CSEA-induced hypotension during cesarean. This finding provides a safe, simple and economic approach to manage CSEA-induced hypotension during cesarean section. 


\section{Materials and Methods}

\section{Inclusion criteria}

For this study, the charts of pregnant women were reviewed when they were admitted to the Third Affiliated Hospital of Guangzhou Medical University and the Sixth Affiliated Hospital of Sun Yat-Sen University for cesarean section. The general inclusion criteria for present study were as follows: patients' gestational age between 37 to 40 weeks, single fetus and American Society of Anesthesia (ASA) grade I-II. For those patients who were volunteering participation of the study, the anesthesia consents were completed prior cesarean section. Additional inclusion criteria were: material heart rate was between 55 to 120 beat/min, blood lost during cesarean section was less than $400 \mathrm{ml}$, operation duration was less than $60 \mathrm{~min}$, no rescue effort was made or no change in anesthesia method during anesthesia and cesarean section. A total of 240 patients met the above criteria and were included in present study.

\section{Procedures}

In operating room, IV access was established in patient's upper extremities. Patient's blood pressure was measured multiple times by noninvasive methods in wedge of upper arm in $5 \mathrm{~min}$ duration/measurement, and the baseline value of blood pressure was determined by average of the first three measurements. Electrocardiogram, heart rate recording and pulse oxygen saturation were also set up in each patient and continuously monitored. For anesthesia, the patients were first lying down toward right side. 2\% lidocaine (Lidocaine Hydrochloride Injection, China) was used as local anesthesia. The CSEA was introduced into L3/4 intervertebral space. Injection for spinal anesthesia was 10-12 seconds in duration. Bupivacaine (Bupivacaine Hydrochloride Injection, China) or ropivacaine (Naropin 1.0\%, Sweden) was applied for intrathecal anesthesia. For epidural anesthesia, $2 \%$ lidocaine was used and initial $2 \mathrm{ml}$ of $2 \%$ lidocaine was used as testing dosage. After anesthesia was given, the patients were turned to left side at $20^{\circ}$ for few minutes. The pain blockage level was tested and adjusted at T6 level. The patients were then maintained in supine position until the cesarean section started. During cesarean section, if patients felt painful or uncomfortable, or tightened abdominal muscle tension, an additional $4-8 \mathrm{ml}$ of $2 \%$ lidocaine would be given epidually, and repeated if necessary. After neonatal umbilical cord was clamped, a dose of 0.05-0.10 mg fentanyl (Fentanyl Citrate Injection, China) was given to enforce the anesthesia. A standard dose of 20-unit of oxytocin (Oxytocin Injection, China) was also given intravenously. The decision to use romethamine (Hemabate, USA) intra-uterus injection in attempt to improve uterus contraction was made by the obstetrician.

During cesarean section, $0.5-1 \mu \mathrm{g} / \mathrm{kg}$ of phenylephedrine (Phenylephedrine Hydrochloride Injection, China) was administrated intravenously to prevent patients' hypotension (systolic pressure dropped down below $80 \%$ of baseline). If phenylephedrine was not effective, or the patient's heart rate was below 50 beat $/ \mathrm{min}, 10 \mathrm{mg}$ of ephedrine (Ephedrine Hydrochloride Injection, China), instead of phenylephedrine, would be given intra-muscularly, and repeated if necessary. If above approaches were still not effective, 5-10 $\mu \mathrm{g}$ of epinephrine (Epinephrine Hydrochloride Injection, China) intravenous injection was given immediately to rescue patient's heart rate and blood pressure. These patients were excluded from present study since this approach was considered to be a change in anesthesia method. In addition, epidual analgesia was used after cesarean section in present study.

\section{Grouping}

During cesarean section, the most common four factors that might involve in treatment of hypotension induced by CSEA are analyzed in present study: volume expander, vasoconstrictor (phenylephrine), types of anesthetic used and interval of blood pressure measurement. They are grouped as follows:

Based on the volume expander used, the patients were divided into two groups. Group 1: patients received Ringer' lactate solution (Sodium Lactate Ringer's Injection, China) intravenously only. Infusion volume was determined by preoperative loss, physiological requirement and intraoperative loss. Beside Ringer' lactate solution, Group 2 patients received an additional rapid infusion of hydroxyethyl starch and sodium chloride solution (Voluven, China) with dosage of 10-15 ml/kg at 30 min prior spinal anesthesia.

Depended on the vasoconstrictor (phenylephrine) applied during cesarean section, the patients were divided into three groups. Group 1: Single bolus of phenylephrine was given at dose of $0.5-1 \mu \mathrm{g} / \mathrm{kg}$ when hypotension was detected. Group 2: Preventive 1 $\mu \mathrm{g} / \mathrm{kg}$ phenylephrine was given when CSEA procedure was completed. Single bolus phenylephrine was given as group 1. Group 3: Preventive and single bolus of phenylephedrine as group 2 plus maintenance dose of intravenously by infusion pump. This group of patients were further divided into 2 groups based on dosage as low dosage $0.25 \mu \mathrm{g} / \mathrm{kg} / \mathrm{min}$ and high dosage $0.35 \mu \mathrm{g} / \mathrm{kg} / \mathrm{min}$. The dose of phenylephrine decreased when the patient's uterus start to be sutured and stop when the abdomen closed.

Based on anesthetic used in CSEA, the patients were divided into two groups. Group 1: a total of $2.7 \mathrm{ml}$ solution mixed with $1.8 \mathrm{ml}$ of $0.5 \%$ bupivacaine and $0.9 \mathrm{ml}$ of $10 \%$ glucose solution ( $10 \%$ Glucose Injection, China). Group 2, a total of $2.4 \mathrm{ml}$ solution mixed with $1.2 \mathrm{ml}$ of $1 \%$ ropivacaine, $0.8 \mathrm{ml}$ of $10 \%$ glucose solution and $0.4 \mathrm{ml}$ of cecbrospinal fluid.

The patients were divided into 2 groups based on the interval of blood pressure measurement as Group 1: 3 min and Group 2: $5 \mathrm{~min}$.

The entire 240 patients enrolled in present study were randomly assigned into $2 \times 3 \times 2 \times 2=24$ parties. Each party contained 10 patients with varying parameters. 
Demographic information including patients's age, height, weight and body mass index, as well as clinical syndromes of hypotension, nausea, vomiting, aspiration during the anesthesia were recorded. Total amount of phenylephrine and romethamine administration, the continuous dosage of phenylephrine, the intraoperative epidural dosage, the infused volume before anesthesia, the total liquid volume during the operation, the maternal blood loss and urine output. The level of blockage of touch and pressure sense when pain blockage at T6 were also recorded prior cesarean section. When the neonatal umbilical cord was clamped, the $\mathrm{pH}$ and base excess (BE) value of the neonatal umbilical venous blood were documented. Apgar score at 1 min and 5 min Apgar were also recorded.

\section{Statistics analysis}

A SPSS17.0 software was applied for statistics analysis in present study. The multivariable linear regression analysis with stepwise selection is chosen so the most significant factor can be identified among multiple options for prevention of hypotension. To establish initial equation of the largest standardized coefficient factor, the dependent variable was designed as the incidence of hypotension, and the independent variables contained 18 parameters, including volume expander, vasoconstrictor (phenylephrine), types of anesthetic used and interval of blood pressure measurement, as well as patient's demographic information (Table 1). Using stepwise analysis, the significant levels for enter was set at $\alpha_{\text {entry }}=0.05$ and for removal was $\alpha_{\text {remove }}=0.15$, which matched the requirement of cumulative probability of standardized residual income model [13]. In order to avoid collinearity as much as possible, conditional index (CI) value less than 15 were used as additional inclusion criteria for collinearity of the multiple linear regression model.

After equation of the largest standardized coefficient factor was obtained, the entire 240 patients with varying parameters were reenter and the incidence of hypotension for each group of patients was calculated, then correlated with $\mathrm{pH}, \mathrm{pO}_{2}$ and $\mathrm{BE}$ in neonatal umbilical venous blood, as well as $1 \mathrm{~min}$ and 5 min Apgar score of the newborn, using student one-way ANOVA. A p value less than 0.05 was considered to be significant difference.

\section{Results}

There was no incidence of respiratory depression or reflux aspiration during cesarean section in all patients.

There were 18 independent variables in the multiple linear regression model (Table 1). The scatterplot for the distribution of hypotension in the standardized expected value and the standardized residuals was shown in Figure 1. The figure showed that a majority of variables are randomly distributed in range of scope of \pm 2 , indicating they are suitable for further analysis.

Based on the $\alpha_{\text {entry }}, a_{\text {remove }}$, all patients were sorted out in five models and showed in Table 2. Because of CI $<15$, Model 3 was selected (Table 3). In Model 3, the standardize coefficient of the variable was as follow: continuous dosage of phenylephrine (-1.929), total quantity of phenylephrine (1.836), management of vasoconstrictor (-0.314) (Table 4).

The multiple linear regression equation was generated as:

Incidence of hypotension $=1.033-29.984 \times$ continuous dose of phenylephrine $+1.095 \times$ phenylephrine total $-0.779 \times$ management of vasoconstrictor, adjusted $\mathrm{R}^{2}=0.911$.

There are three factors to be involved in the incidence of hypotension among 18 independent variables. They are the continuous dose of phenylephrine, total amount of phenylephrine and management of vasoconstrictor. This equation also indicates that the major factor to affect the incidence of hypotension is the continuous dose of phenylephrine.

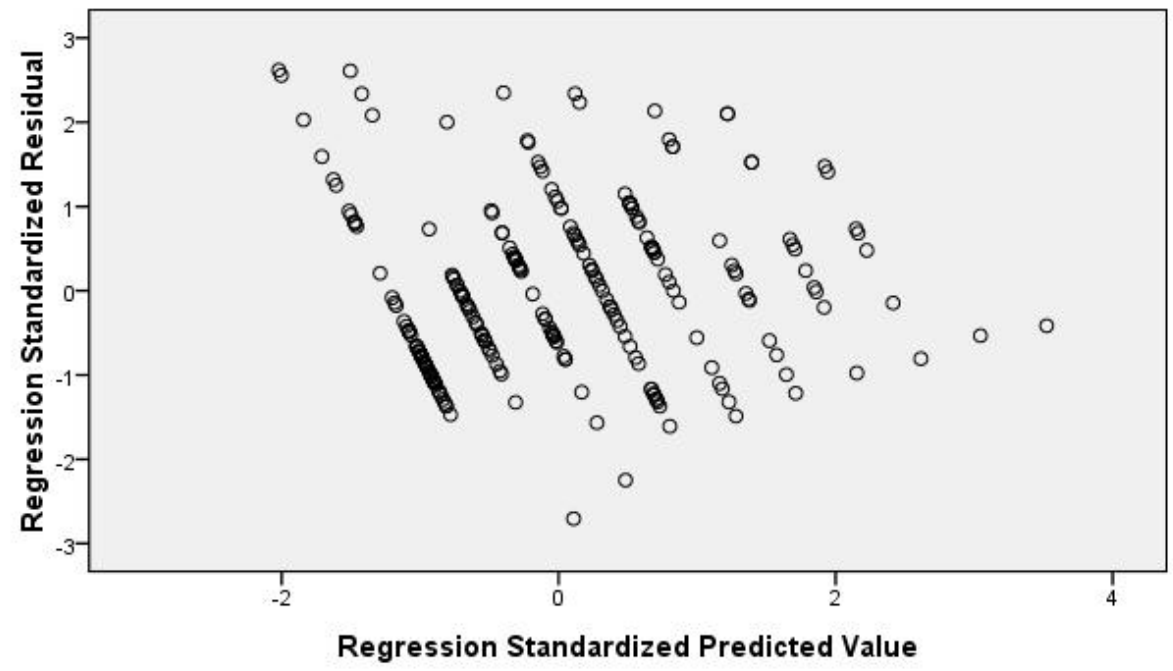

Dependent Variable: incidence of hypotension

Figure 1: The scatterplot of hypotension in the standardized expected value and the standardized residuals 


\begin{tabular}{|c|c|c|}
\hline Variables & mean & std \\
\hline \# Incidence of hypotension & 2.39 & 2.032 \\
\hline Volume management & 1.50 & 0.501 \\
\hline LA used in SA & 1.50 & 0.501 \\
\hline $\begin{array}{l}\text { Management of } \\
\text { vasoconstrictor } \\
\text { (phenylephrine) }\end{array}$ & 2.00 & 0.818 \\
\hline Weight(kg) & 68.14 & 7.806 \\
\hline Age (y) & 29.99 & 4.448 \\
\hline Height $(\mathrm{cm})$ & 158.86 & 4.836 \\
\hline Body mass index $(\mathrm{kg} / \mathrm{m} 2)$ & 26.9841 & 2.63540 \\
\hline $\begin{array}{c}\text { Continuous dose of } \\
\text { phenylephrine }(\mu \mathrm{g} / \mathrm{kg} / \mathrm{min})\end{array}$ & .0917 & 0.13071 \\
\hline $\begin{array}{c}\text { Total dosage of } \\
\text { phenylephrine }(\mu \mathrm{g} / \mathrm{kg})\end{array}$ & 5.1688 & 3.40558 \\
\hline $\begin{array}{c}\text { Total dosage of } \\
\text { romethamine }(\mu \mathrm{g} / \mathrm{kg})\end{array}$ & 7.5 & 50.75 \\
\hline $\begin{array}{l}\text { Liquid volume before } \\
\text { anesthesia }(\mathrm{ml} / \mathrm{kg})\end{array}$ & 9.0053 & 4.89365 \\
\hline $\begin{array}{l}\text { Liquid volume after } \\
\text { anesthesia }(\mathrm{ml} / \mathrm{kg})\end{array}$ & 9.5581 & 2.96324 \\
\hline Total liquid volume ml/kg) & 18.5634 & 4.52827 \\
\hline Blood loss (ml/kg) & 3.1595 & 0.48317 \\
\hline $\begin{array}{l}\text { Intraoperative epidural } \\
\text { dosage (ml) }\end{array}$ & 4.11 & 3.058 \\
\hline $\begin{array}{l}\text { Block level of touch as the } \\
\text { pain block level at T6 }\end{array}$ & 11.80 & 2.146 \\
\hline $\begin{array}{c}\text { Block level of pressure as } \\
\text { pain block level at T6 }\end{array}$ & 14.43 & 1.208 \\
\hline Time of operation (min) & 42.51 & 7.672 \\
\hline
\end{tabular}

\#:the dependent variable

Table 1: Dependent variables and independent variables $(n=240)$

\begin{tabular}{|c|c|c|c|c|c|}
\hline Mode 1 & $\mathbf{R}$ & $\begin{array}{c}\text { R } \\
\text { Square }\end{array}$ & $\begin{array}{l}\text { Adjusted } \\
\text { R Square }\end{array}$ & $\begin{array}{l}\text { Std. Error } \\
\text { of the } \\
\text { Estimate }\end{array}$ & $\mathbf{P}$ \\
\hline 1 & $.536^{\mathrm{a}}$ & .287 & .284 & 1.719 & 0.000 \\
\hline 2 & $.942^{\mathrm{b}}$ & .887 & .886 & .687 & 0.244 \\
\hline 3 & $.955^{c}$ & .912 & .911 & .606 & 0.184 \\
\hline 4 & $.957^{\mathrm{d}}$ & .916 & .914 & .594 & 0.201 \\
\hline 5 & $.958^{\mathrm{e}}$ & .917 & .916 & .591 & 0.408 \\
\hline \multicolumn{6}{|c|}{$\begin{array}{l}\text { a. Predictors: (Constant), continuous dose of } \\
\text { phenylephrine }\end{array}$} \\
\hline \multicolumn{5}{|c|}{$\begin{array}{l}\text { b. Predictors: (Constant), continuous dose of } \\
\text { phenylephrine, total dosage of phenylephrine }\end{array}$} & \\
\hline \multicolumn{5}{|c|}{$\begin{array}{l}\text { c. Predictors: (Constant), continuous dose of } \\
\text { phenylephrine, total dosage of phenylephrine, } \\
\text { management of vasoconstrictor }\end{array}$} & \\
\hline \multicolumn{5}{|c|}{$\begin{array}{l}\text { d. Predictors: (Constant), continuous dose of } \\
\text { phenylephrine, total dosage of phenylephrine, } \\
\text { management of vasoconstrictor, LA used in SA }\end{array}$} & \\
\hline \multicolumn{5}{|c|}{$\begin{array}{l}\text { e. Predictors: (Constant), continuous dose of } \\
\text { phenylephrine, total dosage of phenylephrine, } \\
\text { management of vasoconstrictor, LA used in SA, time of } \\
\text { operation }\end{array}$} & \\
\hline
\end{tabular}

Table 2: Incidence of hypotension 


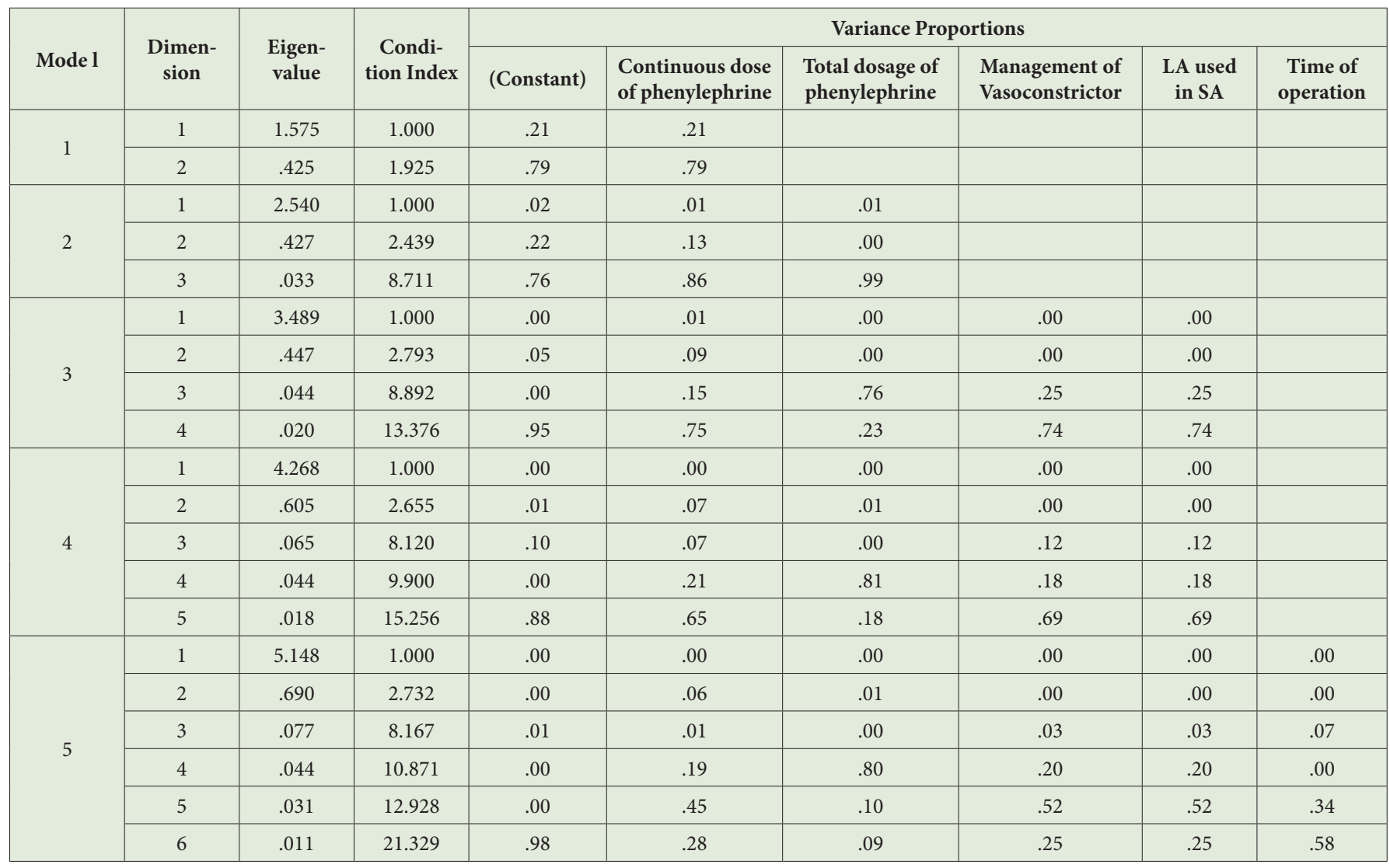

Table 3: Incidence of hypotension

The incidence of hypotension was then calculated and compared between Group 1, Group 2 and Group 3 and was $3.53 \pm 2.02,2.76$ $\pm 1.81,0.88 \pm 1.17$, respectively. The incidence of hypotension in Group 3 patients (both low dose of $0.25 \mu \mathrm{g} / \mathrm{kg} / \mathrm{min}$ and high dose of $0.35 \mu \mathrm{g} / \mathrm{kg} / \mathrm{min}$ together) was significantly lower than Group 1 and Group 2 patients $(\mathrm{p}<0.05)$. No significant difference was detected in incidence of Group 3 patients between low dose $(0.25 \mu \mathrm{g} / \mathrm{kg} / \mathrm{min})$ and high dose $(0.35 \mu \mathrm{g} / \mathrm{kg} / \mathrm{min})(\mathrm{p}>0.05)$.

\begin{tabular}{|c|c|c|c|c|c|c|c|c|}
\hline & \multirow[t]{2}{*}{ Model } & \multicolumn{2}{|c|}{$\begin{array}{l}\text { Unstandardized } \\
\text { Coefficients }\end{array}$} & \multirow{2}{*}{$\begin{array}{c}\text { Standardized } \\
\text { Coefficients }\end{array}$} & \multirow{2}{*}{ t } & \multirow[t]{2}{*}{ Sig. } & \multicolumn{2}{|c|}{ Collinearity Statistics } \\
\hline & & B & Std. Error & & & & Tolerance & VIF \\
\hline \multirow[b]{2}{*}{1} & (Constant) & 3.151 & .136 & & 23.234 & .000 & & \\
\hline & $\begin{array}{c}\text { continuous dose of } \\
\text { phenylephrine }\end{array}$ & -8.333 & .851 & -.536 & -9.794 & .000 & 1.000 & 1.000 \\
\hline \multirow{3}{*}{2} & (Constant) & -.125 & .107 & & -1.169 & .244 & & \\
\hline & $\begin{array}{l}\text { continuous dose of } \\
\text { phenylephrine }\end{array}$ & -34.060 & .802 & -2.191 & -42.482 & .000 & .180 & 5.568 \\
\hline & $\begin{array}{l}\text { total dosage of } \\
\text { phenylephrine }\end{array}$ & 1.090 & .031 & 1.827 & 35.428 & .000 & .180 & 5.568 \\
\hline \multirow{4}{*}{3} & (Constant) & 1.033 & .169 & & 6.121 & .000 & & \\
\hline & $\begin{array}{c}\text { continuous dose of } \\
\text { phenylephrine }\end{array}$ & -29.984 & .861 & -1.929 & -34.805 & .000 & .121 & 8.263 \\
\hline & $\begin{array}{l}\text { total dosage of } \\
\text { phenylephrine }\end{array}$ & 1.095 & .027 & 1.836 & 40.348 & .000 & .180 & 5.571 \\
\hline & $\begin{array}{l}\text { management of vasocon- } \\
\text { strictor (phenyle-phrine) }\end{array}$ & -.779 & .094 & -.314 & -8.286 & .000 & .259 & 3.860 \\
\hline \multirow{5}{*}{4} & (Constant) & 1.379 & .199 & & 6.938 & .000 & & \\
\hline & $\begin{array}{c}\text { continuous dose of } \\
\text { phenylephrine }\end{array}$ & -30.128 & .847 & -1.938 & -35.576 & .000 & .121 & 8.287 \\
\hline & $\begin{array}{l}\text { total dosage of } \\
\text { phenylephrine }\end{array}$ & 1.102 & .027 & 1.846 & 41.224 & .000 & .179 & 5.601 \\
\hline & $\begin{array}{l}\text { management of vasocon- } \\
\text { strictor (phenyle-phrine) }\end{array}$ & -.780 & .092 & -.314 & -8.446 & .000 & .259 & 3.860 \\
\hline & LA used in SA & -.242 & .077 & -.060 & -3.150 & .002 & .995 & 1.005 \\
\hline
\end{tabular}




\begin{tabular}{|c|c|c|c|c|c|c|c|c|}
\hline & \multirow{2}{*}{ Model } & \multicolumn{2}{|c|}{$\begin{array}{l}\text { Unstandardized } \\
\text { Coefficients }\end{array}$} & \multirow{2}{*}{$\begin{array}{c}\text { Standardized } \\
\text { Coefficients } \\
\text { Beta }\end{array}$} & \multirow[t]{2}{*}{$\mathbf{t}$} & \multirow[t]{2}{*}{ Sig. } & \multicolumn{2}{|c|}{ Collinearity Statistics } \\
\hline & & B & Std. Error & & & & Tolerance & VIF \\
\hline \multirow{6}{*}{5} & (Constant) & 1.808 & .291 & & 6.217 & .000 & & \\
\hline & $\begin{array}{l}\text { continuous dose of } \\
\text { phenylephrine }\end{array}$ & -30.015 & .843 & -1.931 & -35.593 & .000 & .120 & 8.323 \\
\hline & $\begin{array}{l}\text { total dosage of } \\
\text { phenylephrine }\end{array}$ & 1.099 & .027 & 1.841 & 41.328 & .000 & .178 & 5.617 \\
\hline & $\begin{array}{l}\text { management of vasocon- } \\
\text { strictor (phenyle-phrine) }\end{array}$ & -.780 & .092 & -.314 & -8.500 & .000 & .259 & 3.860 \\
\hline & LA used in SA & -.241 & .076 & -.059 & -3.148 & .002 & .994 & 1.006 \\
\hline & time of operation & -.010 & .005 & -.038 & -2.010 & .046 & .991 & 1.009 \\
\hline
\end{tabular}

a. Dependent Variable: incidence of hypotension

Table 4: Coefficients of the multiple linear regression equation

\section{Outcome correlation with newborn' parameters}

After the continuous dose of phenylephrine was identified as the main factor by multiple linear regression equation in maternal hypotension after CSEA, we regrouped patients according to the dose of phenylephrine used. The patients were divided into three groups: no continuous dose group (Group 1, $\mathrm{n}=160$ ), continuous dose of $0.25 \mu \mathrm{g} / \mathrm{kg} / \mathrm{min}$ group (Group 2, $\mathrm{n}=40$ ) and continuous dose of $0.35 \mu \mathrm{g} / \mathrm{kg} / \mathrm{min}$ group (Group 3, $\mathrm{n}=40$ ). The $\mathrm{BE}$ and $\mathrm{pH}$ in neonatal umbilical venous blood, as well as 1 and $5 \mathrm{minutes}$ of Apgar score of the newborn in three groups were within the normal range, although the $\mathrm{pH}$ of newborn's umbilical venous blood in Group 2 and Group 3 was significant higher than Group $1(P<0.05)$. There was no significant difference in BE of umbilical venous blood between groups $(P>0.05)$ in Apgar1 or Apgar5 of the newborn (Table 5).

\begin{tabular}{|c|c|c|c|c|c|c|c|}
\hline \multirow{2}{*}{$\begin{array}{c}\text { Dependent } \\
\text { Variable }\end{array}$} & \multirow{2}{*}{$\begin{array}{c}\text { (I)continuous } \\
\text { dose of } \\
\text { phenylephrine }\end{array}$} & \multirow{2}{*}{$\begin{array}{c}\text { (J)continuous } \\
\text { dose of } \\
\text { phenylephrine }\end{array}$} & \multirow{2}{*}{$\begin{array}{l}\text { Mean } \\
\text { Difference } \\
(\mathrm{I}-\mathrm{J})\end{array}$} & \multirow[b]{2}{*}{ Std. Error } & \multirow[b]{2}{*}{ Sig. } & \multicolumn{2}{|c|}{ 95\% Confidence Interval } \\
\hline & & & & & & $\begin{array}{l}\text { Lower } \\
\text { Bound }\end{array}$ & $\begin{array}{l}\text { Upper } \\
\text { Bound }\end{array}$ \\
\hline \multirow{6}{*}{$\mathrm{pH}$} & \multirow{2}{*}{ Group1 } & Group2 & $.017^{\star}$ & .005234 & .041 & -.021 & -.001 \\
\hline & & Group3 & $.012^{\star}$ & .005234 & .021 & -.022 & -.001 \\
\hline & \multirow{2}{*}{ Group2 } & Group1 & .107 & .005234 & .041 & .001 & .021 \\
\hline & & Group3 & .142 & .006620 & .830 & -.014 & .011 \\
\hline & \multirow{2}{*}{ Group3 } & Group1 & .121 & .005234 & .021 & .001 & .022 \\
\hline & & Group2 & .142 & .006620 & .830 & -.011 & .014 \\
\hline \multirow{6}{*}{ BE } & \multirow{2}{*}{ Group1 } & Group2 & .331 & .355 & .352 & -1.03 & .37 \\
\hline & & Group3 & .469 & .355 & .188 & -.23 & 1.17 \\
\hline & \multirow{2}{*}{ Group2 } & Group1 & .331 & .355 & .352 & -.37 & 1.03 \\
\hline & & Group3 & .800 & .449 & .076 & -.09 & 1.69 \\
\hline & \multirow{2}{*}{ Group3 } & Group1 & .469 & .355 & .188 & -1.17 & .23 \\
\hline & & Group2 & .800 & .449 & .076 & -1.69 & .09 \\
\hline \multirow{6}{*}{ APGAR1 } & \multirow{2}{*}{ Group1 } & Group2 & .025 & .058 & .665 & -.09 & .14 \\
\hline & & Group3 & .025 & .058 & .665 & -.09 & .14 \\
\hline & \multirow{2}{*}{ Group2 } & Group1 & -.025 & .058 & .665 & -.14 & .09 \\
\hline & & Group3 & .000 & .073 & 1.00 & -.14 & .14 \\
\hline & \multirow{2}{*}{ Group3 } & Group1 & -.025 & .058 & .665 & -.14 & .09 \\
\hline & & Group2 & .000 & .073 & 1.00 & -.14 & .14 \\
\hline \multirow{6}{*}{ APGAR5 } & \multirow{2}{*}{ Group1 } & Group2 & -.006 & .011 & .586 & -.03 & .02 \\
\hline & & Group3 & -.006 & .011 & .586 & -.03 & .02 \\
\hline & \multirow{2}{*}{ Group2 } & Group1 & .006 & .011 & .586 & -.02 & .03 \\
\hline & & Group3 & .000 & .014 & 1.00 & -.03 & .03 \\
\hline & \multirow{2}{*}{ Group3 } & Group1 & .006 & .011 & .586 & -.02 & .03 \\
\hline & & Group2 & .000 & .014 & 1.00 & -.03 & .03 \\
\hline
\end{tabular}

* The mean difference is significant at the 0.05 level

Table 5: Multiple Comparisons 


\section{Discussion}

It's well known that nausea and vomiting during cesarean section are important risk factors for maternal aspiration pneumonia and therefore infant health. Both nausea and vomiting has been shown to closely associate with and could be the first sign of maternal hypotension during anesthesia [1]. For example, Mrinalini et al. [3] reported that maternal hypotension is an important factor of nausea and vomiting before child delivery, and is the only factor after child delivery. Therefore, the prevention of maternal hypotension during spinal anesthesia is important not only to maintain tissue perfusion but also to prevent aspiration pneumonia. The present study focused on the following important aspects.

\section{Establishment of Model}

Linear regression is a popular statistic analysis to determine the relationship of dependent and independent, and several well documented variants have been developed. Among these, multiple linear regression analysis provides advantage in that it can reveal the relationship from a dependent variable to other, multiple independent variables. Multiple factors have been shown to contribute to maternal hypotension after CSEA during the cesarean section. By using multiple linear regression approach, we successfully identified that the continue administration of phenylephrine is the most important factor contributing to prevention of maternal hypotension after CSEA during the cesarean section. This conclusion is proven, for the first time in a mathematical model in present study.

In practice, two major treatments for maternal hypotension after CSEA during cesarean section are volume expander and vasoconstrictor administration. Other factors might be associated with treatment of maternal hypotension after CSEA during the cesarean section include type of anesthetic used in spinal anesthesia (SA) and interval of blood pressure measurement. These four factors were included in our initial analysis. They are randomly assigned into 24 combinations in group of patients to determine independent of group. Based on the scatter plot (Figure 1), a majority of variables are randomly distributed in range of vertical scope of \pm 2 without correlation between expected value and residual value. Hence the linear regression equation generated from these variables meets original assumption that they are well correlated in

linear relationship with well homogeneity of variance and matching each other. The multi-collinear analysis also showed that the maximum value of condition index (CI) of all the independent variable in Model 3 are less than 15, and the variance inflation factor (VIF) are less than 10, indicating multi-collinear is small and the independent variables is poorly correlated. Therefore this equation is suitable to apply in present study.

\section{Prevention of maternal hypotension}

The standardization of the coefficients in Model 3 for continuous dose of phenylephrine, total dosage of phenylephrine, management of vasoconstrictor are $-1.929,1.836$ and -0.314 respectively (Table 4 ). This suggested that continuous dose of phenylephrine play a major role for dependent variable i.e. the incidence of hypotension in present study. In addition, because additional amount of phenylephrine was used to correct the maternal hypotension, severe hypotension is expected to use higher dosage of phenylephrine to maintain blood pressure in normal range. Hence, the value of standardized coefficients for total dosage of phenylephrine and incidence of hypotension increased proportionally. In other hand, the type of anesthesia has little effect on the incidence of hypotension.

Previous studies showed that infusion of $15-30 \mathrm{ml} / \mathrm{kg}$ intravenously, 15 to 30 minutes prior spinal-epidural anesthesia decreases the incidence of maternal hypotension. Because of in advance of monitoring techniques, some authors have different opinions regarding management of maternal hypotension but volume expander in recent years. Using ultrasonic Doppler techniques, Tamilselvan etc. [4] compared the efficiency of $1500 \mathrm{ml}$ crystalloid, $500 \mathrm{ml}$ colloid and $1000 \mathrm{ml}$ colloid infusion by monitoring maternal cardiac output and corrected flow time. This study showed that, although these three methods had the ability to increase maternal cardiac output after spinal anesthesia particularly in $1000 \mathrm{ml}$ colloid infusion, all three infusions didn't have effect in prevention of maternal hypotension. Similar observation was reported by Wendy etc. [5]. In this study, volume was expanded by infusion of 200/0.5 hydroxyethyl starch solution in dosage of $15 \mathrm{ml} / \mathrm{kg}$ prior anesthesia. Although maternal cardiac output was significantly increased when compared to group without volume expansion, the incidence of hypotension between with and without volume expansion group was similar, as well as the $\mathrm{pH}$ and $\mathrm{BE}$ value of venous blood in the newborn's umbilical cord. Other studies [6,7] suggested that prevention of maternal hypotension by expanding volume prior anesthesia had similar effect during anesthesia. On other hand, Muzlifah etc. [8] suggested that similar effect on preventing material hypotension by infusion of lactated Ringer's solution in $10 \mathrm{ml} / \mathrm{kg}$ or in $15 \mathrm{ml} / \mathrm{kg}$, and the larger volume expansion prior anesthesia is encouraged. Therefore, preventing maternal hypotension after SA by expanding volume remains further investigation. The present study supported the former because the independent variable for volume expansion was excluded from equation, indicating volume expansion prior anesthesia has no effect on prevention of maternal hypotension.

There are controversies in the effects of volume expansion combined with vasoconstrictor in prevention of maternal hypotension after CSEA $[9,10]$. On one hand, McDonald etc. [11] showed that phenylephrine combined with volume expansion by infusion of $1 \mathrm{~L}$ crystals or $1 \mathrm{~L}$ colloid had no effect on maternal cardiac output, incidence of maternal hypotension and major indexes in maternal and newborns. On another hand, Gunusen etc. [12] reported, incidence of hypotension, material nausea and vomiting are lower in patients treated with ephedrine in $1.25 \mathrm{mg} / \mathrm{min}$ combined with crystals $1000 \mathrm{ml}$ after SA in comparison to other 
two groups which prefilled crystals in $20 \mathrm{ml} / \mathrm{kg}$ or colloids $500 \mathrm{ml}$ prior SA, although no difference in the blood gas analysis from neonatal umbilical cord artery or venous blood is observed.

Macarthur etc. [2] suggested that vasoconstrictor use alone, either phenylephrine or ephedrine, by continuously venous infusion, can maintain maternal blood pressure after spinal anesthesia and is more effective than single dose use. Alternatively, we manage patient with phenylephrine in dosage of $1 \mathrm{ug} / \mathrm{kg}$ at starting of spinal injection, followed by continuous dose at a rate of 0.25 or 0.35 $\mathrm{ug} / \mathrm{kg} / \mathrm{min}$ intravenously so the former minimizes incidence of maternal hypotension induced by CSEA due to vascular dilation, and the latter avoids blood pressure fluctuation during cesarean section. The approach is more effective than administration of phenylephrine via repeated single bolus or continuously infusion [14-17]. Because approximately 600-800ml blood volume will be entered back into maternal circulation due to contraction of the uterus after vagina delivery [18], this amount is selfvolume expansion is usually enough to maintain blood pressure, so usually external volume expansion is not necessary. During cesarean section, this physiological process may be interfered and the patient is in a relative volume depressive status. The vascular dilatation effect of CESA may argument this effect, inducing hypotension during cesarean section. Short-acting vasoconstrictor administration overcomes vascular dilatation, may also have effects on uterus vessels, helping to push these extra-volume back to circulation. This approach is especially benefit in patients with hypertension or impaired cardiac function, since overall cardiac burden in these patients would not be over-loaded.

All the medications used in our study are the routine medications for obstetric anesthesia. There is no significant difference in umbilical cord $\mathrm{pH}$ and $\mathrm{BE}$ value, suggesting the vasoconstrictor is safe and feasible for both mother and neonatal.

The low cost of phenylephrine provides another advantage. It can be used to replace expensive colloid solution to prevent the maternal hypotension after CSEA.

In summary, continuous dosage of phenylephrine administration is an effective, safe and low cost approach to prevent maternal hypotension after CSEA for elected cesarean section. It can be reached by administration of phenylephrine $1 \mu \mathrm{g} / \mathrm{kg}$ at starting of spinal injection, followed by continuous dose of 0.25 or $0.35 \mu \mathrm{g} / \mathrm{kg} / \mathrm{min}$ intravenously.

\section{References}

1. Joy L, James F, Richard T (2007) Practice Guidelines for Obstetric Anesthesia: An Updated Report by the American Society of Anesthesiologists Task Force on Obstetric Anesthesia. J Anesthesiology 106: 843-63.

2. Alison J Macarthur (2008) Gerard W. Ostheimer "What's New in Obstetric Anesthesia" Lecture. J Anesthesiology 108: 777-85.

3. Balki M, Kasodekar S, Dhumne S, Carvalho JC (2007) Prophylactic Granisetron Does Not Prevent Postdelivery Nausea and Vomiting During Elective Cesarean Delivery Under Spinal Anesthesia. J Anesth Analg 104: 679-83.

4. Tamilselvan P, Fernando R, Bray J, Sodhi M, Columb M (2009) The Effects of Crystalloid and Colloid Preload on Cardiac Output in the Parturient Undergoing Planned Cesarean Delivery Under Spinal Anesthesia: A Randomized Trial. J Anesth Analg 109: 1916-21.

5. Teoh WH, Sia AT (2009) Colloid Preload Versus Coload for Spinal Anesthesia for Cesarean Delivery: The Effects on Maternal Cardiac Output. J Anesth Analg 108: 1592-8.

6. Carvalho B, Mercier FJ, Riley ET, Brummel C, Cohen SE (2009) Hetastarch co-loading is as effective as pre-loading for the prevention of hypotension following spinal anesthesia for cesarean delivery. J Int J Obstet Anesth 18:150-5.

7. Siddik-Sayyid SM, Nasr VG, Taha SK, Zbeide RA, Shehade JM, et al. (2009) A randomized trial comparing colloid preload to coload during spinal anesthesia for elective cesarean delivery. J Anesth Analg 109: 1219-24.

8. Muzlifah KB, Choy YC (2009) Comparison between preloading with $10 \mathrm{ml} / \mathrm{kg}$ and $20 \mathrm{ml} / \mathrm{kg}$ of Ringer's lactate in preventing hypotension during spinal anaesthesia for caesarean section. Med J Malaysia 64: 114-7.

9. Mercier FJ1, Bonnet MP, De la Dorie A, Moufouki M, Banu F, et al. (2007) Spinal anaesthesia for caesarean section: fluid loading, vasopressors and hypotension. Ann Fr Anesth Reanim 26: 688-93.

10. Loubert C (2012) Fluid and vasopressor management for Cesarean delivery under spinal anesthesia: continuing professional development. Can J Anaesth 59: 604-19.

11. McDonald S, Fernando R, Ashpole K, Columb M (2011) Maternal cardiac output changes after crystalloid or colloid coload following spinal anesthesia for elective cesarean delivery: a randomized controlled trial. Anesth Analg 113: 803-10.

12. Gunusen I, Karaman S, Ertugrul V, Firat V (2010) Effects of fluid preload crystalloid or colloid) compared with crystalloid co-load plus ephedrine infusion on hypotension and neonatal outcome during spinal anaesthesia for caesarean delivery. Anaesth Intensive Care 38: 647-53.

13. Lu Wen Dai, Wu Hi (2006) SPSS for windows statistical analysis (3rd edition), Beijing, Electronic Industry Press 300.

14. Langesæter E, Rosseland LA, Stubhaug A (2008) Continuous Invasive Blood Pressure and Cardiac Output Monitoring during Cesarean Delivery: A Randomized, Double-blind Comparison of Low-dose versus High-dose Spinal Anesthesia with Intravenous Phenylephrine or Placebo Infusion. J Anesthesiology 109: 856-63.

15. Ngan Kee WD, Lee A, Khaw KS, Ng FF, Karmakar MK, et al. (2008) A randomized double-blinded comparison of phenylephrine and ephedrine infusion combinations to maintain blood pressure during spinal anesthesia for cesarean delivery: the effects on fetal acid-base status and hemodynamic control. Anesth Analg 107: 1295-302.

16. Ngan Kee WD, Tam YH, Khaw KS, Ng FF, Critchley LA, et al. (2007) Closed-loop feedback computer-controlled infusion of phenylephrine for maintaining blood pressure during spinal anaesthesia for caesarean section: a preliminary descriptive study. Anaesthesia 62: 1251-6.

17. Allen TK, George RB, White WD, Muir HA, Habib AS (2010) A double-blind, placebo-controlled trial of four fixed rate infusion regimens of phenylephrine for hemodynamic support during spinal anesthesia for cesarean delivery. Anesth Analg 111: 1221-9.

18. Jaffe RA, Samuels SI (2005) Stanford clinical anesthesia, Tianjin: Tianjin Science and Technology Translation and Publishing Corporation, 770. 